\title{
2. Time and Technology: The Temporalities of Care
}

\author{
Gabriele Schabacher
}

\begin{abstract}
By focusing the temporalities of care, the chapter analyzes a special relation between time and technology that underlies the making and persisting of media and infrastructures. I propose to differentiate between four types of care practices with corresponding different temporal patterns that are highly relevant for the functioning of technological systems in the past and present. First, the retrospective response to unforeseen interruptions (repair); second, the prospective routine procedure to prevent all forms of disorder (maintenance); third, a neglect of care that leads to devaluating infrastructure (abandonment) as well as - fourth-forms of revaluation in changing contexts (repurposing). Taking the new Berlin airport BER as an example, it will be shown that infrastructures exhibit different layers of temporality formed by these cyclic and repetitive processes of care and their transforming effects. Thus, even the performance of the most "hardwired," late modern technology systems is crisscrossed by temporal regimes that stem from older, non-modern temporalities of care.
\end{abstract}

Keywords: repair, maintenance, care, infrastructure, cultural techniques, abandonment

In this article, I analyze the relations between time and technology that underlie the making and persisting of media and infrastructures by focusing on the temporalities of care. I take up the notion of the hardwiredness of infrastructures in the sense of their consolidation and material embeddedness, raising the question of the practices responsible for achieving and maintaining technical structures. This implies understanding hardwiredness not as a fixed state of being of materially "wired" artifacts or digital infrastructures,

Volmar, A. and K. Stine (eds.), Media Infrastructures and the Politics of Digital Time: Essays on Hardwired Temporalities. Amsterdam: Amsterdam University Press, 2021 DOI 10.5117/9789463727426_CHO2 
but rather as a network effect with relative duration brought about by specific types of labor. Seen in this light, the effect of being "hardwired" appears not only in processes of industrialization and standardization since the nineteenth century but also in older, premodern cultural techniques responsible for the conservation of things. I understand caring activities in the sense of a certain type of constant, repetitive, and comparably slow work that tends to be invisible and naturalized in the mundane routines of everyday life. The advantage of such a perspective for media studies is that it enables insight into the various temporalities of infrastructures, which, as I argue, form a vertical layering of different ages within one and the same infrastructure, leaving several strata to be uncovered.

Recent research in science and technology studies, urban studies, architectural studies, and the history of technology has shifted attention to processes of upkeep and repair as highly relevant to the functioning and stabilization of organizations and infrastructures. ${ }^{1}$ However, questions of repair and upkeep are less addressed with respect to the functioning of digital infrastructures. ${ }^{2}$ For this reason, I take up the insights of repair studies, especially as developed in the fields of architecture and urban studies, in order to show their relevance for a discussion of hardwired infrastructures under digital conditions. Repair studies analyzes the care of physical infrastructures, such as buildings and transport systems, and acknowledges the materiality of those things, people, and codes out of which also "the digital" is made, whether cables, workflows, or programs. Such a perspective has already been productive in studying the work places and labor practices of early computing, for example in analyzing the so-called software crisis of the 1960 s as "essentially a maintenance problem."

The concept of care has recently been addressed with regard to ethical implications and the type of work it generates, together with the question of who cares for whom and the affective relationships that go along with this practice. According to Maria Puig de la Bellacasa, the three dimensions of care- "labor/work, affect/affections, ethics/politics"—are distributed in all relational situations. ${ }^{4}$ Care work can refer to people (including the care for oneself), 5 things and artifacts, but also to machines and infrastructures. Thus, the gender bias ${ }^{6}$ care work implies, the "invisible work" 7 it goes along with and the "tacit" ${ }^{8}$ knowledge of carers are relevant aspects for an analysis of care work, whether this relates to humans or the realm of material objects. ${ }^{9}$ Care is in general closely linked to concern ${ }^{10}$ and draws on affective relations between human and nonhuman actors. Latour's study of the transport system Aramis discloses the affective relationship with technology (the love of technology) as the most important aspect for accomplishing or giving up 
on a project. ${ }^{11}$ Only on the basis of an attachment to a certain thing can an affective relation of care be built. ${ }^{12}$

Studies of care stress two kinds of temporalities involved in caring practices. On the one hand, they refer to the fragility of the material world and processes of decay; on the other hand, they point to the work side of the problem, that is, the array of continual "reordering micro-processes."13 Steven Jackson claims that the temporalities of maintenance and repair blend "the unruly timelines of things." Drawing an analogy between the care of the human body and the repair and maintenance of objects, he describes a temporal relation in which the care of things involves "a staying with in time and place," that means, an adjusting of one's own time to "other temporal flows and processes, including the temporalities of breakdown and decay." Repair-as-care, according to Jackson, implies opening and tying oneself to the "rhythms, flows, and timeliness of another." ${ }^{14}$

Considering these ideas, I propose to differentiate between four types of practices that concern the care for technology and, correspondingly, four different types of temporal patterns. First, the activities of restoring-especially practices of repair - that respond to unforeseen events, ranging from catastrophic situations to ordinary breakdowns and malfunctioning, and rebuild a previous state of affairs. With respect to their temporal logic, these activities can be understood as a retrospective form of care. Second, the practices of maintenance, upkeep, and regular service of technical systems that are intended to prevent all forms of disorder by routine and planned procedures of control. Insofar as these practices are directed toward the future of technology, I will understand them as a prospective form of care. Third, the devaluation of infrastructures through decay and deterioration. These processes exhibit an inversion or negative form, a lack of care characterized by neglect and indifference. Fourth, and sometimes as a result of decay, processes of revaluation and repurposing that I understand as a redirection of care by reusing an existing infrastructural setting.

Although the distinctions between the four different types of caring activities are not clear-cut, I take them to be useful for analyzing temporal regimes of hardwiredness. This offers a perspective on care practices that concentrates on their status as cultural techniques and demonstrates that maintenance carries forward a non-modern notion of care stemming from the cultural techniques in the sense of cultura. In doing so, the article wants to accentuate two general aspects. First, in light of these various temporal patterns of care, hardwired infrastructures appear less as linear, enduring, stable objects and systems than as cyclical and repetitive processes of formation and transformation. Even the most hardwired, late-modern, 
high-technology systems are crisscrossed by different temporal regimes, especially on the level of micro practices that stem from older, non-modern, and, to some degree, more organically and culturally embedded temporalities of care. This becomes obvious in particular with regard to what I will call "maintaining-as-waiting" (warten). Second, different layers of temporality and care practices exist within any single infrastructural setting. These various temporalities and "ages" of infrastructures produce effects of interference, accumulation, and repetition because regimes of work, affective relationships, juridical decisions, lifetimes of components, to name only a few, are not distributed in a coordinated way with regard to actors and goals.

\section{Layered Temporalities: The BER project}

The different layers of temporality inherent in a given material infrastructure can be illustrated by the well-known example of the Berlin Brandenburg Airport. The BER had been under construction since 2006, after its initial planning in 1995. The opening had been postponed several times since 2011 (see Table 2.1). The last target for the official opening date was October 2020, but this again had been called into question because of an internal (leaked) TÜV Rheinland report of 2019 revealing serious safety deficiencies in important technical installations and suggesting an opening not before 2021. ${ }^{15}$ In the public, the BER is known as a case of severe mismanagement, corruption, and poor construction planning and execution. The already long list of construction flaws became longer every day (the TÜV report lists 11,519 technical flaws altogether), and the costs for not bringing the airport into operation amounted to about 36 million euro per month. The Flughafen Berlin Kosten website displayed the rising costs per second in real time. ${ }^{16}$ By 2020 the whole enterprise had cost the taxpayer up to 5.3 billion euro already and would have increased to an estimated 7 billion euro by 2025 .

Yet from an infrastructural perspective, the BER project demonstrates not only mismanagement but also the heterogeneity of the socio-technical "actor-world" in question in a paradigmatic way, ${ }^{17}$ bringing together materials, political parties, contracting companies, reports, and investigations, ${ }^{18}$ as well as considerations of environmental impacts, increases in passenger traffic, design flaws, and costs. The BER project shows the failure to come to mutual and simplifying translations to align all these heterogeneous elements in one direction, namely the completion of the construction project. Instead, each entity operates as a full mediator of the whole process, following its own directions. ${ }^{19}$ 
Table 2.1. Postponement of BER opening dates

\begin{tabular}{ll}
\hline Announcement & Opening \\
\hline September 5, 2006 (original) & October 30, 2011 \\
June 25, 2010 & June 3, 2012 \\
May 7, 2012 & March 17, 2013 \\
October 27, 2012 & October 27, 2013 \\
January 1, 2013 & on/after 2014 \\
January 8, 2014 & on/after 2015 \\
February 24, 2014 & on/after 2016 \\
May 14, 2014 & on/after 2017 \\
December 1, 2014 & 2nd half of 2017 \\
January 21, 2017 & July 10, 1905 \\
December 15, 2017 & October 31, 2020 \\
\hline
\end{tabular}

From Wikipedia, Berlin Brandenburg Airport, https://en.wikipedia.org/wiki/Berlin_Brandenburg_Airport, accessed November 11, 2020.

With regard to the temporalities of infrastructures, the BER is interesting in at least three respects. First, it demonstrates the difficulty of consolidating and stabilizing a project at all, that is, coming to a (temporary) state of "hardwiring." The BER project failed even to arrive at this point of upkeeping an achieved stability, as the heterogeneity of citizens, organizational actors, laws and prescriptions, environmental organizations, and material and technical components could not be aligned long enough to complete the project in the first place. Second, the time it took to build the infrastructure itself encompassed processes of decay. The passenger information monitors already had to be replaced because they had reached the end of their lifetime.$^{20}$ In the airport's underground train station, several "ghost trains" had to be run each day to provide fresh air and prevent mold from accumulating. ${ }^{21}$ Regimes of planned obsolescence, as seen in the case of the monitors, interfered with the longevity of the construction process; cycles of maintenance had to be executed to simulate usage, although the structures were not officially open to the public. Third, the time that passed itself altered perspectives on the future of the project. New calculations of projected passenger traffic, for instance, now demand a restructuring of the whole airport area. The so-called "master plan 2040"22 calls for a rewiring, so to speak, of the whole project before it was even completed, merging the current areas of the Berlin Schönefeld Airport with the unfinished BER and adding a "midfield" and other buildings to create an even bigger airport. The map combines existing buildings, buildings planned until 2030, and desired future buildings, thereby showing the site as a "contested gathering of many 
conflicting demands" where processes of design constantly interfere with what already has been built. ${ }^{23}$

On a more general level, the example shows different layers of temporality within a single infrastructure. According to Steward Brand, in How Buildings Learn, the very idea of architectural permanence is misleading. Instead, the adaptability of any architecture has to be seen as a continual flow of transformations. "All buildings grow" and age, says Brand, but "different parts of buildings change at different rates." ${ }^{24}$ Brand differentiates between the layers of "site," "structure," "skin," "services," "space plan," and "stuff."25 Whereas the geographical setting, or site, of a building is long-lasting, the layer of services, such as electrical wiring, plumbing, sprinkler system, and ventilation, must be renewed every seven to fifteen years. This level of services caused severe problems in completing the BER, as monitors, cables, and even safety helmets became obsolete during the process. The "shearing layers of change" have the effect of the building "tearing itself apart." ${ }^{26}$ With regard to the BER, we can see shearing layers of different time scales not only with respect to the physical dimensions of the infrastructure but also their socio-technical aspects, such as bureaucratic procedures, prescriptions, investigations, and planning.

The temporal regimes involved in the BER example concern, on the one hand, infrastructures of temporality, that is, the governing of time through plans, management routines, and maintenance cycles. On the other hand, the example illustrates the temporalities of infrastructure, that is, the different lifespans of the involved entities, the transforming effects of flaws, mistakes, and corruption on the project as a whole and the (organic) processes of decay and repurposing. A notable example of repurposing is that the uncompleted airport became a tourist attraction. One could book tours via bus or bike and, as of March 2017, 1.55 million visitors had been shown around the airport. ${ }^{27}$ A perspective on the relations of technology and time can therefore provide for a fruitful perspective on infrastructural networks, adding to spatial, topological, and environmental approaches insights on the ephemerality of their existence.

\section{Repair}

As we have seen with respect to the BER project, different layers of temporality exist within the same infrastructural setting. In the following, I describe in more depth the four practices of care outlined above, starting with the practice of repair. 
How one assesses the importance of repair in the present it is first of all a question of perspective. Under conditions of scarcity, repair has been ubiquitous for a long time in history, ${ }^{28}$ and it still is in countries of the Global South, whereas in Western industrialized countries "the continuities between the hidden and ongoing cultures of repair that characterize urban life outside of catastrophic states ... tend to be dramatically underplayed." ${ }^{29}$ As a consequence, infrastructures tend to be regarded as "hardwired," that is orderly, fixed, and stable. However, repair activity is not less relevant in the present, but only less visible. The international repair movement (repair cafés, the website iFixit, for example), ${ }^{30}$ while claiming a fundamental "right to repair" and taking up ideas from discourses on sustainability, commonism, and the do-it-yourself-scene, ${ }^{31}$ focuses on household items (toasters, printers) or consumer products (iphone, ipad) and their planned obsolescence rather than on machines and infrastructures. More fundamentally, Steven Jackson calls for a "broken world thinking," a perspective on the principal fragility and vulnerability of the material world that takes its "always-almost-falling-apart" as the starting point for a rethinking of repair activities. ${ }^{32}$

With respect to the temporalities of infrastructure, two aspects have to be emphasized. First, the constitutive ex-post-character (Nachträglichkeit) of repair (re-parare, in the sense of a reconstruction ${ }^{33}$ ), which is responsible for the epistemic quality of repair, as knowledge of breakdowns or accidents only becomes evident in the aftermath of an irritation. ${ }^{34}$ For this reason, I call this practice retrospective care. Second, and nevertheless, the grade of belatedness and visibility differs. Roughly speaking, Western societies believe and imagine themselves to be living in more stable environments (despite all the makeshift solutions in daily life), whereas people in the Global South engage openly in repair as a ubiquitous, mundane activity.

Regarding the BER example, the obsolescence of products forced repair work. Besides the 750 monitors mentioned, 16,849 fire detectors had to be exchanged at a cost of 1.6 million euro because go percent of them had reached the end of their permitted service life. This turned out to be quite lucrative for the respective firms, as they could build the airport several times, so to speak. 35

\section{Abandonment}

Abandonment refers to the processes of devaluation that technologies and infrastructures undergo as a result of a lack of care. ${ }^{6}$ When infrastructures 
are not cared for, they decay. Or more precisely, other processes take over. While the BER was not used as an airport, grass could grow in places where there was otherwise intense traffic. The heterogeneous actors were not aligned in one direction, but follow their own paths.

The concept of decay raises questions concerning the status of materiality and its "hardwiredness." Regarding the material ecology of subway signs, for example, the workers did not experience the signs' "materiality" but were immersed in a "malleable material flux" of different material properties, including the walls, metal brackets, and signboards, as well as screws, plugs, and glue cement. ${ }^{37}$ From an architectural and urbanist perspective, such a flux can be understood as "architecture's 'life' and 'death." Instead of relying on architecture's attested "material durability," this means to concentrate on the relation of architecture to "decay, deterioration, and destruction." 38 In reference to Michael Thompson's analysis of the complex processes of valuation and devaluation of things, ${ }^{39}$ Stephen Cairns and Jane M. Jacobs highlight "matter" and "mattering," that is, the dimension of materiality and the processes of valuation, as two concepts to explain the "relative durability" of built structures, which in their opinion is linked to a specific temporality:

Architecture's relative durability does not exempt it from the principle of mutable value, but it does ensure that architecture generally "circulates" via processes of reinvestment, restoration, and revaluation - more slowly through its ebb and flow. As a consequence, buildings are regularly out of time — unused, unloved, unappreciated, devalued—but still very much in place. ${ }^{40}$

Infrastructural decay should not be seen simply as a natural by-product of the time passing. In her study on the aging infrastructure of a NASA space project, Marisa Cohn shows that it requires active work to bring about the end-of-life of such a huge system. Infrastructural decay, here, "is composed of multiple lifetimes of different parts of the system — hardware, software, code, organizational processes, programming languages, institutions, careers-all of which are entangled and are aging or obsolescing at different rates. ${ }^{141}$

With respect to the logic of abandonment, the specific obduracy of built structures seems interesting, as it serves to make visible the lack of care. An obsolete building can be understood as an "obduracy-in-obsolescence," being "in place but out of time."42 It cannot be made to disappear from sight in simple ways: "Unlike other waste objects, which can be managed or rendered invisible by being pushed into a garbage bin, stored in the attic, compacted in a landfill, or biodegraded, buildings often, resolutely and 
publicly, stay in view and in place regardless of their economic and public evaluations. ${ }^{13}$ This can also be seen at the BER. The buildings are physically there, they cannot be easily removed, although the expected increase in the number of passengers would demand another, bigger airport. So we only see the demolition (Rückbau) of selected parts. ${ }^{44}$

The distinction between different time scales of infrastructure provides a further perspective on the obduracy and stability of infrastructures. In his "multiscalar approach," Paul N. Edwards refers to the different temporalities of human life, history, and geology. ${ }^{45}$ Infrastructures exhibit stability and durability only on the level of human and historical times, whereas on geological or "long-term historical" scales infrastructures and nature present themselves as less discernible from each other, up to the point of their identification where "[N]ature is ... in some sense the ultimate infrastructure." ${ }^{m 6}$ Nevertheless, Edwards' view on infrastructure's fragile, ephemeral qualities is informed by an understanding of technical malfunctioning (he uses the concepts of "irregularity," "breakdown," etc.) rather than an interest in processes of decay and deterioration or material relics and ruins, which are already beyond a logic of functioning and purpose. However, certain organic processes represent symptoms of abandonment, such as the grass growing between the concrete joints at the BER, and can be seen as the interference of other time regimes within the logic of infrastructural becoming.

Processes of decay shift our attention from disturbance and disaster, as more or less discontinuous and abrupt events, to slower and often unnoticed temporal processes of change. Nevertheless, as any amateur gardener knows, nature reconquers man-made structures steadily. Processes of abandonment can therefore be seen as an inverted or negative form of care, characterized by indifference and a lack of concern.

\section{Repurposing}

In his autobiography, Roland Barthes recalls the allegory of the Argo as an object of continual, transformative processes of care:

A frequent image: that of the ship Argo (luminous and white), each piece of which the Argonauts gradually replaced, so that they ended with an entirely new ship, without having to alter either its name or its form. The ship Argo is highly useful: it affords the allegory of an eminently structural object, created not by genius, inspiration, determination, evolution, but by two modest actions (which cannot be caught up in any mystique of 
creation): substitution (one part replaces another, as in a paradigm) and nomination (the name is in no way linked to the stability of the parts). ${ }^{47}$

What Barthes invokes in the ship that the Argonauts permanently rework is the perspective on a processuality of technology and architecture that is barely noticeable, in that it draws on not radical upheaval or individual genius, but steady transformation. Although Barthes argues from a structuralist perspective that underlines the analogous and language-based quality of substitution within the same paradigm, it is nevertheless possible to think of a ship's material quality and the necessity to improvise with respect to repair and maintenance work due to scarce resources on the high seas.

This transformative aspect has also been addressed as technology's "fluidity" and "adaptability."${ }^{\text {} 8} 8$ With regard to mobile phone repair in Dhaka and Kampala, Steven Jackson argues, "the phone that emerges at the end is demonstrably not the same device." The work done on the mobile phone changes it: "The phone has become in effect a different object: new but not radically new, separated from and connected to its past by the forms of breakdowns, maintenance, and repair through which it has passed." ${ }^{m 9}$ The same is true for all the processes connected to the reworking of software and digital infrastructures, such as updating, and jumpering..$^{50}$ This work of transformation generally implies the need to improvise, that is, workarounds and makeshift solutions that include moments of bricolage, artisan tinkering, and creativity. ${ }^{1}$

Regarding the BER, one could say that the project did not stay the "same" over the time of its construction. Even more, it had not been "unique" from the beginning. For Latour, "to design is always to redesign," there is "something medial in design" so that it never creates ex nihilo..$^{2}$ Rather, artifacts are conceived as "complex assemblies of contradictory issues," disputed matters of concern, that we are still unable to design in all their complexity. ${ }^{53}$ Against this background, one could even say that the BER from the beginning is a project of re-designing, as it starts from "something that exists first as a given, as an issue, as a problem." ${ }^{44}$ And this "given" is Berlin's "airport situation," which the new BER is supposed to change for the better.

A further aspect regarding the transformative nature of care concerns the re-direction of its goals, the "creative" processes of adaptation and repurposing of artifacts and technologies toward other contexts. ${ }^{55}$ As the emphasis on first design neglects "the extraordinary life stories" of objects and technologies in other cultures, there is the need to account for 'creole' technologies" as fundamental parts of change: "[M]ost change is taking place by the transfer of techniques from place to place. ${ }^{m 6}$ 
Interestingly enough, such transformations not only solve problems but also generate new ones, which can be illustrated by a historical example. With reference to the difficulties of the shipment of plants at the end of the eighteenth century, Maren Mayer-Schwieger has shown that the legendary mutiny on the HMS Bounty was more or less a direct result of transformations on the ship. In an effort to prevent the breadfruit plants being shipped from dying, as had been the case in previous attempts at transporting live plants, radical measures were taken. Primarily, the captain's cabin became the storage space for hundreds of flowerpots. This arrangement severely disturbed order aboard the Bounty, in particular, the hierarchical priority of the captain, and the resulting mutiny again led to a failure of plant transportation. ${ }^{57}$

Concerning the specific type of care in question, three aspects can be emphasized. First, processes of re-structuring necessarily belong to the usage of infrastructures and artifacts. Second, they can generate radical effects and conflicts because of the involved processes of de- and revaluation of certain elements of the network, such as the captain's cabin. And third, to focus on processes of re-structuring and re-purposing calls into question the assumption that there can be something like a "new" artifact. Something is new only in relation to what is already there. As for the temporal dimensions of care for technology, re-structuring processes can therefore be understood in terms of the redirection of care to new goals by re-using an existing and potentially devaluated infrastructural setting.

\section{Maintenance}

If we now take a closer look at the set of caring activities involved in maintenance, ${ }^{5}$ upkeep, and regular service of technical systems, we can see that caring for technology takes a prospective form, here, as it is directed to stabilizing the uncertain future of an artifact, technology, or system. Caring in this respect demands a focus on not only the functional relations to technology but also the "moral relations." 59 It seems as if the question of care can only be linked to technology if the latter is situated in an area "beyond" the realm of mere technical functioning.

Forms of maintenance often go along with an affective relationship to the maintained object, in particular on the level of micro practices. The subjects involved regularly develop a certain "sense" for the thing cared for, which provides a sort of diagnosing tool. The service operator responsible for Paris' water management system (SAGEP), for example, claims that the sluices 
of Paris' water supply had "talked" to him via the old servo-controls. ${ }^{60}$ In a similar way, some of the engineers who worked for decades within the aging Saturn mission spacecraft infrastructure were "accustomed to computing work that would be difficult to find still practiced elsewhere. ${ }^{\text {"1 }}$ What these examples illustrate is the fact that although control may be digitalized, the stabilization of the systems as a whole is dependent on procedures that refer to its material substrate as well as to the acquired skills of the caretakers (which again implies an essentially temporal dimension).

To elaborate on the specific temporality of maintenance and upkeep, the etymology of the word waiting (German warten) is of special interest. The verb warten in German has two meanings: first, to maintain, to upkeep; and second, to wait, to hold out. As I argue, it is this dimension of waiting that underlies and determines the temporal logic of maintenance processes ${ }^{62}$ In the Deutsches Wörterbuch, the most comprehensive dictionary of the German language, begun by the Grimm Brothers in 1854, we find an entry on warten of no less than 42 columns. The article describes the usage in the sense of waiting ("to await what is coming") only in the final part, while the preceding pages are centered on the relation between directed attention and the practices of guarding, watching, and caring. Interestingly, people are also said to be maintained ("Personen warten") in the sense of being cared for or administered. ${ }^{63}$ This includes caring for the sick, children, animals, gardens, and - more common to today's usage - objects. To speak of care with respect to things, the Grimm Brothers note, means to care for or just to deal with them constantly. ${ }^{64}$ This last mentioned aspect establishes a link between temporal and affective dimensions of maintenance, as this type of practice creates and is, therefore, embedded in a sort of habit.

The process of maintaining-as-waiting in the sense of the German warten denotes a specific form of concern characterized by attentiveness toward the object of care, be it a thing, a person, an animal, or, we can add, a machine. ${ }^{65}$ This attention takes the form of a close and constant contact with objects cared for. We thus deal with an activity that derives its temporality from the objects it follows in an effort at preservation. Referring to Heidegger's notion of dwelling as "sparing and preserving," 66 one could say that Beingin-the-World in the sense of dwelling can be understood as form of care for the environment as such.

In general, maintaining-as-waiting (warten) always proceeds in the present, but it is, at the same time, directed prospectively toward the future of the object cared for. This can be seen as a fundamental difference to the practice of repair that responds to a disturbance or, at least, irritation, and to forms of neglect of care that leave the former object of care to itself, 
whereas forms of repurposing may again involve a future for the object cared for. The practices of maintaining-as-waiting (warten) cultivate a type of concern tuned to preventing harm by regularly caring for objects and people, such as through the oiling and cleaning of machines and the proper nutrition and hygienic measures of people. The lifetimes of artifacts and people, in effect, coincide with the processes of their maintenance. Cost-intensive infrastructures, such as weapon systems, aircrafts, and busses, thus tend to live "eternally," if they are cared for in a proper way. This can be seen by the continued usage of taxis, busses, and even bicycles sorted out in Western societies in the Global South, ${ }^{67}$ or in the necessity to actively end their lifetimes. ${ }^{68}$ However, this longevity as an effect of maintenance practices reminds us of the basic fragility of things. Things do not "exist" in an uncomplicated way but only because of the work and care invested in them.

Although maintenance work can be described with respect to temporalities of different infrastructural entities, it is of course also relevant to point to the infrastructures of temporality that are in turn involved in processes of maintenance. Two aspects can be distinguished.

First, and in contrast to the possible longevity of artifacts and machines, consumer products have implanted limits that are known as planned obsolescence, and are conditioned to become cyclically out fashioned in increasingly shorter intervals. This phenomenon belongs to the logic of capitalist value creation, for which it would be fatal if objects were cared for in a relevant sense. This is one reason why today's call for "repairability"69 and "maintainability,"70 that is, the production of maintainable products (e.g., the Fairphone with interchangeable parts), ${ }^{71}$ did not manage to gain a deeper impact until now. Accordingly, the so-called life cycle management might be taken to amount to nothing more than the attempt to exploit each phase of life of the object (planned obsolescence inclusively). Although it may seem at first glance as the revival of older practices of re-using, known from an economy of scarcity, the idea of life cycle management is informed by cost-effectiveness and not by a logic to spare things. ${ }^{2}$ Nevertheless, also in the economic field, there are tendencies to see maintenance not as a "necessary evil," but rather as a potential to minimize material and energy consumption, ${ }^{73}$ controlled by "life cycle 'big data' analytics." ${ }^{74}$

Second, processes of technical maintenance are often informed by infrastructures of temporality. As we saw with the Berlin Airport example, these procedures follow certain cycles (for example, the necessary ventilation runs of the airport train). They are structured according to the logic of intervals of time and therefore dependent on a certain type 
of clocking that organizes their execution, repetition, and control. Seen in this light, maintenance procedures might also belong to the realm of planning, logistics, and management, and they might thus be adapted to a cybernetic logic of control.

\section{Conclusion}

In analyzing the hardwiredness of infrastructures, I have distinguished several layers of temporalities that go along with four different practices of care. I have discussed repair as an activity that aims to restore order retrospectively. While this represents the normal state of things in the Global South or under preindustrial conditions, Western industrialized societies often exhibit a belief in the stability of infrastructures. The phenomenon of decay, in turn, has been addressed as a form of abandonment that results from devaluation and lack of care, whereas processes of transformation and repurposing have been analyzed as complementary forms of revaluation and therefore redirections of care. For the activity of maintenance, I have assumed a dialectics of non-modern concepts (the logic of concern as a type of attentiveness to things in the form of waiting) and modern concepts (that integrate maintenance into logistical cycles of management).

Considering practices of maintaining-as-waiting (warten) of devices, machines, and large technical systems in particular, we get closer to basic processes within the realm of the organic, where cultura in the sense of care and concern for the soil in agriculture is important for the flourishing of plants, animals, and humans. Such a perspective highlights the logic and importance of cultural techniques to our modern understanding of culture, society, and technology. ${ }^{75}$ Maintaining-as-waiting (warten) would then refer to a specific "Eigenzeitlichkeit," or temporality, of things, demanding that one holds out and allows things to take their time. ${ }^{7}$

This also implies a non-modern understanding of maintainability, for which the general adaptivity of things is central: "Age plus adaptivity is what makes a building come to be loved."77 The possibility of modification is responsible for the adjustment of buildings and infrastructures to the changing conditions of time. ${ }^{7}$ Consequently, in terms of care, "a concern for maintainability translates material permanency into sociotechnical sustainability, and recognizes that stability, like reality, is 'an active verb."'79 We have to develop an understanding of "appropriate technology," where "fluid object[s]" remain open to change and dismantling during their development. ${ }^{80}$ Taken as matters of concern, things are on the move 
in the very basic sense of "moving project[s]." ${ }^{81}$ As I have argued, maintenance in the sense of waiting could then be seen as a set of extremely undervalued practices of care and concern that are important for the continued existence of culture, society, and technology, including the continued existence of digital cultures. From this perspective, hardwired infrastructures appear less as stable and durable systems than as ongoing processes of transformation. Even high-technology infrastructures, thus, are consisting of and crisscrossed by different temporal regimes that include non-modern, more organically and culturally embedded temporalities of care.

\section{Notes}

1. See for example Christopher R. Henke, "The Mechanics of Workplace Order: Toward a Sociology of Repair," Berkeley Journal of Sociology 44 (2000): 55-81; Stephen Graham and Nigel Thrift, "Out of Order: Understanding Repair and Maintenance," Theory, Culture \& Society 24, no. 3 (2007): 1-25; Steven J. Jackson, "Rethinking Repair," in Media Technologies. Essays on Communication, Materiality, and Society, ed. Tarleton Gillespie, Pablo J. Boczkowski, and Kirsten A. Foot (Cambridge, MA/London: MIT Press, 2014), 221-239; Stefan Krebs, Gabriele Schabacher, and Heike Weber, eds. Kulturen des Reparierens. Dinge - Wissen - Praktiken (Bielefeld: transcript, 2018); Andrew L. Russell/ Lee Vinsel, "After Innovation, Turn to Maintenance," Technology and Culture 59, no. 1 (2018): 1-25.

2. For notable exceptions see Neil Pollock et al., "Post Local Forms of Repair. The (Extended) Situation of Virtualised Technical Support," Information and Organization 19, no. 4 (2009): 253-276; Jason Farman, "Repair and Software: Updates, Obsolescence, and Mobile Culture's," continent. 6, no. 1 (2017): 20-24. With respect to new media's logic of constant actualization, see Wendy Chun, Updating to Remain the Same. Habitual New Media (Cambridge/London: MIT Press, 2016).

3. Nathan Ensmenger, The Computer Boys Take Over. Computers, Programmers, and the Politics of Technical Expertise (Cambridge, MA/London: MIT Press, 2010), 225. See also Thomas Haigh, "The Chromium-Plated Tabulator. Institutionalizing an Electronic Revolution, 1954-1958," IEEE Annals of the History of Computing 23, no. 4 (2001): 75-104.

4. María Puig de la Bellacasa, Matters of Care: Speculative Ethics in More Than Human Worlds (Minneapolis/London: University of Minnesota Press, 2017), 5.

5. Foucault, Michel, The Care of the Self. The History of Sexuality 3 (Harmondsworth and others: Penguin Books, 1990); see also Annemarie Mol, Ingunn Moser, and Jeannette Pols, eds. Care in Practice. On Tinkering in Clinics, Homes and Farms (Bielefeld: transcript, 2010). 
6. Emily K. Abel and Margret K. Nelson, eds. Circles of Care: Work and Identity in Women's Lives (New York: State University of New York Press, 1990).

7. Susan Leigh Star and Anselm Strauss, "Layers of Silence, Arenas of Voice: The Ecology of Visible and Invisible Work," Computer Supported Cooperative Work (CSCW) 8, no. 1-2 (1999): 9-30.

8. Michael Polanyi, The Tacit Dimension (New York: Doubleday Company, 1966).

9. Jérôme Denis and David Pontille, "Material Ordering and the Care of Things," Science, Technology \& Human Values 40, no. 3 (2015): 338-367; Nicky Gregson, Alan Metcalfe, and Louise Crewe, "Practices of Object Maintenance and Repair: How Consumers Attend to Consumer Objects within the Home," Journal of Consumer Culture 9, no. 2 (2009): 248-272.

10. María Puig de la Bellacasa, Matters of Care, 42-48; see also Bruno Latour, "From Realpolitik to Dingpolitik-An Introduction to Making Things Public," in Making Things Public. Atmospheres of Democracy. Catalogue of the show at ZKM, ed. Bruno Latour and Peter Weibel (Cambridge, MA: MIT Press, 2005), 4-31.

11. Bruno Latour, Aramis, or the Love of Technology. Transl. Catherine Porter (Cambridge, MA, London: Harvard University Press, 1996).

12. Antoine Hennion, "Attachments, You Say? ... How a Concept Collectively Emerges in One Research Group," Journal of Cultural Economy 10, No. 1 (2017): 112-121.

13. Denis and Pontille, "Material Ordering and the Care of Things," 355 and 353.

14. Steven J. Jackson, "Speed, Time, Infrastructure. Temporalities of Breakdown, Maintenance, and Repair," in The Sociology of Speed, ed. Judy Wajcman and Nigel Dodd (Oxford: Oxford University Press, 2017), 169-205, here: 179 and 183. On the interference of temporal regimes of embodied human experience and the materialities of technology, see also the contributions of Nicole Starosielski and Marisa Leavitt Cohn in this volume.

15. Thorsten Metzner, "Hauptstadtflughafen. TÜV hält BER-Terminplan für stark gefährdet," Der Tagesspiegel, April 11, 2019. Available at https:// www.tagesspiegel.de/berlin/hauptstadtflughafen-tuev-haelt-ber-terminplan-fuer-stark-gefaehrdet/24210992.html (accessed June 15, 2019). The TÜV (Technischer Überwachungsverein) Rheinland is a technical inspection association that provides inspection and product certification services according to international standards. The BER indeed opened on October 31, 2020.

16. The calculation is based on an extrapolation from the last reliable data and the assumption of a linear progression of costs. See the website "Flughafen Berlin (BER) Kosten," https://www.flughafen-berlin-kosten.de/ (accessed June 15, 2019).

17. See Michel Callon's analysis of the unsuccessful project to develop an electric vehicle in the 1970s, Michel Callon, "The Sociology of an Actor-Network. The Case of the Electric Vehicle," in Mapping the Dynamics of Science and Technology: Sociology of Science in the Real World, ed. Michael Callon, John Law, and Arie Rip (Basingstoke: Macmillan, 1986), 19-34. 
18. A parliamentary committee of inquiry investigated the mismanagement between 2012 and 2016 and published a report of 1.269 pages in June 2016, Bericht des 1. Untersuchungsausschusses des Abgeordnetenhauses von Berlin - 17. Wahlperiode-zur Aufklärung der Ursachen, Konsequenzen und Verantwortung für die Kosten- und Terminüberschreitungen des im Bau befindlichen Flughafens Berlin Brandenburg Willy Brandt (BER), Drucksache 17/3000, June 14, 2016. Available at https://www.parlament-berlin. de/C1257B55002AD428/vwContentbyKey/206D7oE8863Co6F9C12580C60051E19A/\$FILE/d17-3000.pdf (accessed May 27, 2018).

19. See also Bruno Latour, "Trains of Thought: Piaget, Formalism, and the Fifth Dimension," Common Knowledge 6, no. 3 (1996): 170-191, here: 175; Gabriele Schabacher, "Mobilizing Transport. Media, Actor-Worlds, and Infrastructures," Transfers. International Journal of Mobility Studies 3, no. 1 (Spring 2013): 75-95.

20. "Berlin: 750 Monitore am BER schon veraltet," Spiegel Online, http://www. spiegel.de/wirtschaft/unternehmen/berlin-750-monitore-am-ber-schonveraltet-a-1198359.html (accessed November 8, 2019).

21. “S-Bahn-Lüftungsfahrt zum Airport BER," Berliner Verkehrsblätter 6o, no. 4 (2013): 67.

22. See "Master Plan BER 2040," https://www.berlin-airport.de/de/presse/ publikationen/geschaeftspartner/2018/2018-masterplan-ber-2040.pdf (accessed June 15, 2019).

23. Bruno Latour and Albena Yaneva, "'Give me a gun and I will make all buildings move': An ANT's View of Architecture," in Explorations in Architecture: Teaching, Design, Research, ed. Reto Reiser (Basel: Birkhäuser, 2008), 80-89, here: 86.

24. Stewart Brand, How Buildings Learn: What Happens After They're Built (London: Penguin, 1994), 10, 12.

25. Brand, How Buildings Learn, 13 .

26. Brand, How Buildings Learn, 13 .

27. Sonja Gurris, "Führung auf dem Flughafen BER. Der Airport, über den Berlin lacht," NTV, December 2, 2017. Available at https://www.n-tv.de/reise/DerAirport-ueber-den-Berlin-lacht-article20156588.html (accessed June 15, 2019). Interestingly enough, this experience was not offered on the international site.

28. Reinhold Reith and Georg Stöger, "Einleitung. Reparieren - oder die Lebensdauer der Gebrauchsgüter," Technikgeschichte 79, no. 3 (2012): 173-184.

29. Graham and Thrift, "Out of Order," 9. As Jörg Potthast has shown with regard to the work of air traffic controllers, even the seemingly "normal case" exhibits high degrees of disorder, Jörg Potthast, "Ethnography of a Paper Strip: The Production of Air Safety," Science, Technology \& Innovation Studies 4, no. 1 (2008): 47-68, here: 51f.

30. Sigrid Kannengießer, "Repair Cafés - Reflecting on Materiality and Consumption in Environmental Communication," in Environmental Communication Pedagogy and Practice, ed. Tema Milstein, Mairi Pileggi, and Eric Morgan (London: Routledge, 2017), 183-194. 
31. For a historical perspective, see Daniela K. Rosner and Fred Turner, "Theaters of Alternative Industry: Hobbyist Repair Collectives and the Legacy of the 196os American Counterculture," in Design Thinking Research: Building Innovators, ed. Hasso Plattner, Christoph Meinel, and Larry Leifer (Berlin/ Heidelberg/New York: Springer, 2015), 59-69.

32. Jackson, "Rethinking Repair," 221 and 222.

33. Entry "repair, v.2," in Oxford English Dictionary, Oxford University Press 2019. Available at https://www.oed.com (accessed November 8, 2019).

34. For the media history of accidents and their reconstruction, see Christian Kassung, ed. Die Unordnung der Dinge. Eine Wissens- und Mediengeschichte des Unfalls (Bielefeld: transcript, 2009).

35. For the Bosch company that was contracted to build the fire detection system and safety technology for about 12 Million Euro the contract has multiplied up to 66.4 Million Euro in 2018, because of supplements due to the postponed opening and pricing on hourly basis (Thorsten Metzner, "Die Mängelliste wird kürzer. Wo es jetzt noch hakt auf der BER-Baustelle," Der Tagesspiegel, June 5, 2019. Available at https://www.tagesspiegel.de/ berlin/die-maengelliste-wird-kuerzer-wo-es-jetzt-noch-hakt-auf-der-berbaustelle/24420576.html (accessed June 19, 2019)).

36. See also Gabriele Schabacher, "Abandoned Infrastructures. Technical Networks beyond Nature and Culture," Zeitschrift für Medien- und Kulturforschung 9, no. 1 (2018): 127-145.

37. Denis and Pontille, "Material Ordering and the Care of Things," $35^{2}$.

38. Stephen Cairns and Jane M. Jacobs, Buildings Must Die. A Perverse View of Architecture (Cambridge, MA/London: MIT Press, 2014), 2 and 1.

39. Michael Thompson, Rubbish Theory: The Creation and Destruction of Value (Oxford and others: Oxford University Press, 1977).

40. Cairns and Jacobs, Buildings Must Die, 49, $5^{8 .}$

41. Marisa Leavitt Cohn, "Convivial Decay: Entangled Lifetimes in a Geriatric Infrastructure," CSCW'16. Proceedings of the 19th ACM Conference on Computer-Supported Cooperative Work \& Social Computing 2016: 1511-1523, here: 1511 and 1513 .

42. Cairns and Jacobs, Buildings Must Die, 111 and 103. On obduracy in urban contexts, see Anique Hommels, Unbuilding Cities. Obduracy in Urban Sociotechnical Change (Cambridge, MA/London: MIT Press, 2008). On ruins and ruination, see Gastón R. Gordillo, Rubble. The Afterlife of Destruction (Durham/London: Duke University Press 2014).

43. Cairns and Jacobs, Buildings Must Die, $5^{8}$.

44. Metzner, "Hauptstadtflughafen. TÜV hält BER-Terminplan für stark gefährdet."

45. Paul N. Edwards, "Infrastructure and Modernity," in Modernity and Technology, ed. Thomas J. Misa, Philip Brey, and Andrew Feenberg (Cambridge, MA: MIT Press, 2003), 185-225, here: 185 and 194.

46. Edwards, "Infrastructure and Modernity," 195 and 196.

47. Roland Barthes by Roland Barthes. Transl. Richard Howard (Berkeley/Los Angeles: University of California Press, 1977), 46. 
48. Marianne de Laet and Annemarie Mol, "The Zimbabwe Bush Pump: Mechanics of a Fluid Technology," Social Studies of Science 30, no. 2 (April 2002): 225-263, here: 225 and 226.

49. Jackson, "Speed, Time, Infrastructure," 179.

50. Farman, "Repair and Software."

51. On workarounds see Gabriele Schabacher, "Im Zwischenraum der Lösungen. Reparaturarbeit und Workarounds," in Workarounds. Praktiken des Umwegs, ed. Holger Brohm, Sebastian Gießmann, Gabriele Schabacher, and Sandra Schramke (Berlin: Philo Fine Arts, 2017), xiii-xxviii; on bricolage see Claude Lévi-Strauss, The Savage Mind (London: Weidenfield and Nicolson, 1966), 16f.; on artisan tinkering Simon Schaffer, "Easily Cracked. Scientific Instruments in States of Disrepair," Isis 102, no. 4 (2011): 706-717, here: 708; on improvisation Henke, "The Mechanics of Workplace Order," 66-69.

52. Bruno Latour, "A Cautious Prometheus? A Few Steps Toward a Philosophy of Design (With Special Attention to Peter Sloterdijk)," in: Proceedings of the 2008 Annual International Conference of the Design History SocietyFalmouth, 3-6 September 20o9, ed. Fiona Hackne, Jonathn Glynne and Viv Minto (Boca Raton: Universal Publishers, 2008), 2-10, here: 4 and 5 .

53. Latour, "A Cautious Prometheus?," 4, 11 and 12.

54. Latour, "A Cautious Prometheus?," 5.

55. See Ben Jervis and Alison Kyle, eds. Make-do and Mend. Archaeologies of Compromise, Repair and Reuse (Oxford: Archaeopress, 2012); Paula Jarzabkowski and Trevor Pinch, "Sociomateriality is 'the New Black': Accomplishing Repurposing, Reinscripting and Repairing in Context," M@n@gement 16, no. 5 (2013): 579-592; David Keller and Maria Dillschnitter, eds. Zweckentfremdung. 'Unsachgemäßer' Gebrauch als kulturelle Praxis (Paderborn: Fink, 2016).

56. Edgerton, Shock of the Old, 38, 43 and 209.

57. Maren Mayer-Schwieger, "Umwege auf See. Zur Pflanzenverschiffung Ende des 18. Jahrhunderts," in Workarounds. Praktiken des Umwegs, ed. Holger Brohm, Sebastian Gießmann, Gabriele Schabacher, and Sandra Schramke (Berlin: Philo Fine Arts, 2017), 146-156.

58. On the history and historiography of maintenance, see Russell and Vinsel, "After Innovation, Turn to Maintenance."

59. Jackson, "Rethinking Repair," 231.

6o. Bruno Latour and Emilie Hermant, Paris ville invisible (La Décourverte: Les Empêcheurs de penser en rond, 1998), 26. On the holistic knowledge involved in care practices, see also Douglas Harper, Working Knowledge. Skill and Community in a Small Shop (Chicago: The University of Chicago Press, 1987); Stefan Krebs, “'Dial Gauge versus Senses 1-o'. German Car Mechanics and the Introduction of New Diagnostic Equipment, 1950-1980," Technology and Culture 55, no. 2 (2014): 354-389.

61. Cohn, "Convivial Decay," 1513.

62. In English one can still find this meaning of caring and guarding in the word waiter (entry “waiter, n.," in Oxford English Dictionary (OED). Oxford 
University Press 2019. Available at https://www.oed.com (accessed November 8,2019$)$ ) as well as in older - today obsolete - meanings of the verb wait as "to (keep) watch" (entry "wait, v.1," OED 2019). The verb maintain, in turn, refers not only to the upkeep of things, but also in general to the actions of supporting, assisting, defending, continuing, prosecuting, preserving, and providing for the sustenance, for example, of an animal (entry "maintain, v.," OED 2019). See also Gabriele Schabacher, "Waiting. Cultural Techniques, Media and Infrastructures," in Cultural Techniques. Spaces, Texts, Collectives, ed. Jörg Dünne, Kathrin Fehringer, Kristina Kuhn, and Wolfgang Struck (London/New York: De Gruyter, 2020), 71-84.

63. Entry "warten," in Jakob und Wilhelm Grimm, Deutsches Wörterbuch, vol. XIII (Leipzig: Hirzel, 1922), column 2137.

64. Grimm, Deutsches Wörterbuch, column 2141.

65. In Being and Time Heidegger describes concern as the fundamental way of Being-in-the-world, Martin Heidegger, Being and Time [1962]. Transl. John Macquarrie \& Edward Robinson (Oxford/Cambridge: Blackwell, 2001), ${ }_{5}^{6}$.

66. Martin Heidegger, "Building Dwelling Thinking," in Martin Heidegger, Poetry, Language, Thought. Transl. Albert Hofstadter (New York and others: Harper \& Row, 1971), 145-161, here: 149.

67. Hans P. Hahn, "Das 'zweite Leben' von Mobiltelefonen und Fahrrädern. Temporalität und Nutzungsweisen technischer Objekte in Westafrika," in Kulturen des Reparierens. Dinge - Wissen - Praktiken, ed. Stefan Krebs, Gabriele Schabacher, and Heike Weber (Bielefeld: transcript, 2018), 105-119.

68. Cohn, "Convivial Decay."

69. Daniela K. Rosner and Morgan Ames, "Designing for repair?: Infrastructures and Materialities of Breakdown," CSCW'14. Proceedings of the 17th ACM Conference on Computer Supported Cooperative Work \& Social Computing, Baltimore, Maryland, USA - February 15-19, 2014: 319-331, here: 319.

70. Denis and Pontille, "Material Ordering and the Care of Things," 358.

71. See the respective website "Fairphone / The phone that cares for people and planet," https://www.fairphone.com/en/ (accessed June 20, 2019).

72. John Stark, "Product Lifecycle Management," in Product Lifecycle Management (Volume 1). 21st Century Paradigm for Product Realisation, third ed., ed. John Stark (London and others: Springer, 2015), 1-29.

73. Shozo Takataa et al., "Maintenance: Changing Role in Life Cycle Management," CIRP Annals 53, no. 2 (2004): 643-655, here: 643.

74. Rajkumar Roy et al., "Continuous Maintenance and the Future-Foundations and Technological Challenges," CIRP Annals 65, no. 2 (2016): 667-688, here: 667 .

75. Bernhard Siegert, Cultural Techniques. Grids, Filters, Doors, and Other Articulations of the Real. Transl. Geoffrey Winthrop-Young (New York: Fordham University Press, 2015).

76. See Michael Gamper and Helmut Hühn, eds. Zeit der Darstellung. Ästhetische Eigenzeiten in Kunst, Literatur und Wissenschaft (Hannover: Wehrhahn, 2014). 
77. Brand, How Buildings Learn, 23 .

78. See also Christopher Alexander, The Timeless Way of Building (New York: Oxford University Press, 1979).

79. Denis and Pontille, "Material Ordering and the Care of Things," 359.

8o. de Laet and Mol, "The Zimbabwe Bush Pump," 235 and 226.

81. Latour and Yaneva, "Give me a gun," 80.

\section{About the Author}

Gabriele Schabacher is Professor of Media and Culture Studies at the Johannes Gutenberg University of Mainz, Germany. Her research interests include the media history of traffic, mobility, and infrastructures, the cultural techniques of repair, and the media history of seriality. Recent co-edited volumes focus on the cultures of repair (2018) and on the practices of workarounds (2017). 
